\title{
Comparative Study on IELTS Academic and CET Writing
}

\author{
Lin Liu \\ College of Foreign Language Education, China West Normal University, Nanchong, Sichuan, China
}

Keywords: IELTS, CET, writing task, band descriptor, scoring criteria, washback effect

\begin{abstract}
Although IELTS academic and CET are both English language tests for higher education students, their differences in the test module and band descriptor cause the washback effects in teaching and learning of English. Through the comparative study of the differences of the writing in the two tests, this paper tries to reflect on the possible washback effects of the band descriptor and scoring criteria on English teaching, and endeavors to explore the possibility to promote Chinese university students’ academic ability through English writing.
\end{abstract}

\section{Introduction}

The IELTS (International English Language Testing System) is an English language assessment for study, migration and work in English speaking countries like UK, USA, Australia, Canada and New Zealand and developed by the British Council. As an internationally acknowledged English language test, IELTS is aligned to CEFR (Common European Framework of Reference for Languages: Learning, Teaching, Assessment). For different purpose, IELTS is divided into IELTS Academic and IELTS General Training. The IELTS band score is equally valued by listening, reading, writing and speaking. The CET (College English Test) is a national English test used to evaluate college non-English major students' English language proficiency. The CET is composed of listening, reading, writing and translation, while speaking test is optional since November, 2016. Among them, writing takes up only $15 \%$ of the total score, the same as translation, while listening and reading each take $35 \%$ of the score. So not enough importance is attached to writing in Chinese college English teaching because of the distribution of score in CET.

Both IELTS Academic and CET involve future possibility of further academic study. For non-English majors, the most important English skills applied in academic study are academic reading and academic writing. Comparing the different writing modules of IELTS Academic and CET writing, the different academic requirement in institutions of China and some English speaking countries can be found.

\section{The differences in IELTS Academic and CET writing}

\subsection{The writing module}

IELTS Academic module writing task is divided into two parts. The test takers are asked to describe some visual information in their own words in Task 1. Those visual information could be graph, table, chart or diagram and Task 1 is a typical academic writing style that most higher education institutions would require in their study and research. For Task 1, the test takers are given 20 minutes to write 150 words. In Task 2, the test takers respond to a point of view or argument or problem in 40 minutes with 250 words.

In each CET test, there is only one writing task. The CET Band 4 asks test takers to describe personal experience or feeling; describe simple picture; give personal opinion on familiar subject; apply common practical writing; discuss and explain and illustrate outline, chart or picture in 120 words. While the CET Band 6 requires test taker to express personal view on general topic; describe chart or picture and further discuss, explain or illustration the outline, chart or picture in 150 words. The time limit on both CET writing tests is 30 minute. 
Although CET Band 4 is taken by university students all over China, the writing task of Band 4 is more like IELTS General Training writing rather than Academic writing, especially the practical writings in CET-4. In recent years, more and more practical writings can be found in CET-4. For example, in June 2016, the three writings of CET-4 are thanks letters and in June 2017, the three writings of CET-4 are about advertisement on selling second-hand goods, which are typical writing tasks type for IELTS General Training. Not much academic approach or creative thinking is demonstrated in the Band 4 writing. Ever since the 2005 reform, graph writing never appears in CET Band 4. All Band 4 writings belong to outline writing, which is to discuss or illustrate the given outline. Even in CET Band 6, the few pictures writing are all cartoons instead of graph, table, chart or diagram. In fact, the ability to describe key features and present an overview about graph, table, chart or diagram is commonly needed in scientific research, but CET writing does not take it into consideration and this may impede the Chinese university students' future academic study, especially when they try to publish academic paper on international journal, they may not be able to clearly state their scientific statistics.

\subsection{The band descriptor and scoring criteria}

Both band descriptors used to measure IELTS Academic writing Task 1 and Task 2 includes criteria on four factors: task achievement, coherence and cohesion, lexical resource, grammatical range and accuracy. The candidates would be rewarded from band 1 to band 9 based on the band descriptor. There is no fail or pass in the IELTS test, but the typical IELTS Academic score for entry most universities in the world for postgraduate study is about 6 . The band descriptor (public version) of band 6 in IELTS Academic writing is:

Task Achievement addressees the requirement of the task; presents an overview with information appropriately selected; presents and adequately highlights key features/ bullet points but details may be irrelevant, inappropriate or inaccurate (Task 1) addressees all parts of the task although some parts may be more fully covered than others; presents a relevant position although the conclusions may become unclear of repetitive; presents relevant main ideas but some may be inadequately developed/ unclear (Task 2) Coherence and Cohesion arrange information and ideas coherently and there is a clear overall progression; Uses cohesive devices effectively, but cohesion within and/ or between sentences may be faulty or mechanical; may not always use referencing clearly or appropriately Lexical Resource uses an adequate range of vocabulary for the task; attempts to use less common vocabulary but with some inaccuracy; makes some errors in spelling and/ or word formation, but they do not impede communication Grammatical Range and Accuracy uses a mix of simple and complex sentence form; makes some errors in grammar and punctuation but they rarely reduce communication.

The difference of band descriptor for Task 1 and Task 2 only lies in task achievement, the other three criterion are the same in both of them. A student language proficiency would be demonstrated consistently in both tasks, so the only difference would just be the response to the different task types. The band descriptors for IELTS writing is very specific for each part.

Although the full score of CET is 710, the exam papers are graded based on 100 score scale. The writing is graded with the highest score of 15 , so the passing score for writing should be 9 . The scoring criteria are classified into five levels. For the passing score, 9, which belongs to the level of 8 score, the band descriptor is: generally addresses the task with some ideas difficult to be identified; words are organized coherently with frequent grammatical errors and some of them are serious mistakes. Compared with IELTS band descriptor, the CET scoring criteria is relatively brief and abstract.

\subsection{The washback effects}

Hughes defined washback effect as "the effect of testing on teaching and learning” (Hughes, 1989). The different requirements lead to different approaches in English teaching and learning. The IELTS candidates are not only required to fully address the task, but also arrange the content in a logical way, so critical thinking is needed. The candidates should not just state personal statements one by one. Instead, they should arrange the ideas and information coherently. In IELTS writing, the writing 
structure "I-R-E" is strongly recommended by teachers and widely used by students. For the "I-R-E" structure, "I" stands for idea, "R" for reason and "E" for example. In order to illustrate the thesis statements, the test takers should either apply inductive and deductive reasoning or example to support his idea or even both. While in CET writing, the logical organization and the reasoning between argument and conclusion are not specifically marked. So cultivating critical thinking would be an important part in IELTS teaching but may not so important in Chinese college English teaching.

Another difference of IELTS and CET is about the lexical range. First, the IELTS writing requires candidates to write more words than CET writing, and the range of vocabulary is required in IELTS writing. The CET does not have specific direction for lexis in band descriptors so the candidates do not necessary need to display a diverse glossary in the writing. Second, for the cohesion criteria, the IELTS test takers should use cohesive devices to avoid repetition in the writing, such as reference and substitution. However, the cohesive devices are not necessary consideration in CET writing grading, so in a much shorter CET writing, the candidates may not intentionally avoid repetition in the writing, which would result in the common phenomenon that test takers constantly repeat key words of the outline in the writing. Generally speaking, candidates of IELTS should be prepared with a larger glossary than the CET candidates.

What CET writing values most is the grammatical accuracy. The accurate application of grammatical rules is the priority of English teaching in China, and it is a long-time tradition. In IELTS band descriptor, not only grammatical accuracy but also grammatical range is elaborated. Accurate complex sentences are necessary in order to achieve band 6 in IELTS. If attempt to compose complex sentence but with errors, the test takers may only be rewarded band 5 for grammatical range and accuracy. The grammatical accuracy in CET writing is important for getting a score above 8 while the proficiency in applying complex sentence is not specifically addressed in the band descriptor, so many Chinese students would try to write simple sentences in order to avoid possible grammar mistakes, which leads to Chinese students find difficulties in elaborating sophisticated conception in English.

\section{Conclusions}

The IELTS Academic is designed to measure whether test takers language proficiency is ready for facing a real English language environment in the future academic study while CET is served as a certification for students reach the English levels specified in the National College English Teaching Syllabuses (NCETS). Academic writing is not a necessary consideration for CET writing because although students take the CET examination, they may just graduate from school and hunt for jobs, even some students would continue with postgraduate study, the publication of academic paper could be written in Chinese.

For many Chinese university science students, they do not receive enough training on academic writing, which hinders their future scientific research. Chinese is not a compulsory course in university study. Even if some universities offer students Chinese course, the focus of such course is always about the appreciation of Chinese classics. English is one of the compulsory courses in every higher education institution in China. Nevertheless, as the touchstone of college English teaching, CET does not address to academic writing, and the CET writing, in a large degree, is marked with consideration of very basic skill such as grammar. The washback effect of CET scoring criteria is that academic writing format and critical thinking are ignored in the college English teaching for general purpose, and college students get nowhere to acquire such skill for future academic study, this may become an obstacle even in their graduation thesis writing. If academic writing features are integrated into CET scoring criteria, it would certainly drive English teachers and students in China to work harder towards this direction, which would, in long term, facilitate Chinese academic research in the world.

\section{References}

[1] British Council, IDP: IELTS Australia and Cambridge English Language Assessment, IELTS 
Writing Task: Band Descriptors (public version), https://www.ielts.org/ielts-for-organisations/ieltsscoring-in-detail

[2] Cai Jigang, Influence of CET Writing Requirement and Scoring Criteria on Chinese Students' Compositions, Journal of PLA University of Foreign Languages, vol. 25, pp. 49-53, 2002

[3] Canagarajah, AS, Critical Academic Writing and Multilingual Students, University of Michigan Press, Ann Arbor, 2002

[4] Heaton J B, Writing English Language Test, Longman Group UK Limited, 1988

[5] Hughes A, Testing for Language Teachers, Cambridge University Press, Cambridge, 1989

[6] The Committee of national College English Test Band 4 and Band 6, Syllabus for national College English Test-Band four and Band six (2016), http://www.cet.edu.cn/file_2016_1.pdf

[7] Wang Qingqing, On the Guiding Significance of IELTS Writing Band Descriptors for College English Writing Teaching, Journal of Jiangxi Institute of Education (Comprehensive), vol. 34, pp. 145-147, 2013 